\title{
The Burden of New Leprosy Cases in India: A Population-Based Survey in Two States
}

\author{
Anil Kumar and Sajid Husain \\ Departments of Biostatistics and Epidemiology and Orthopedic Surgery, National Jalma Institute for Leprosy and \\ Other Mycobacterial Diseases (ICMR), Taj Ganj, Agra, Uttar Pradesh 282001, India
}

Correspondence should be addressed to Anil Kumar; dranil250158@gmail.com

Received 21 January 2013; Accepted 19 February 2013

Academic Editors: D. A. Boakye, S. P. Lim, and N. Micale

Copyright ( 2013 A. Kumar and S. Husain. This is an open access article distributed under the Creative Commons Attribution License, which permits unrestricted use, distribution, and reproduction in any medium, provided the original work is properly cited.

\begin{abstract}
Objectives. To assess the burden of new leprosy cases in India and the efficiency of case detection work by ASHA in general health system. Methods. A sample survey of 804,536 persons was undertaken in 8 districts during 2009-2010: 4 each in Haryana (low endemic for leprosy) and Uttar Pradesh (high endemic for leprosy). About 20\% population was covered from urban areas. Results. The survey suggested that burden of new case detection rate of leprosy in India per 10,000 population could be 4.41 in comparison to 1.09 as per government records. When present observation is adjusted to team performance in rural area, the NCDR increased to 10.64 per 10,000. This leads to suggest that NCDR in India could further increase to 9.76 times when adjusted to team performance. This data suggest that large numbers of early leprosy cases do not reach the health facilities where leprosy treatment is provided, although some chronically ill patients reach late, and thus multibacillary disease is found more in passive reporting. This could also be an indicator of a large number of established cases not being sufficiently self-motivated or lacking knowledge to utilize the free diagnosis and treatment services. Thus, the programme needs to be designed to meet these objectives effectively to better utilize the available services to reduce the leprosy burden. Conclusion. Active survey detected many folds higher leprosy cases in community, and this suggests that the information, education, and communication based approaches have a very minimal effect. If the programme continues to be based on IEC activities, the information should be designed in such a way that most persons suspected to have leprosy can know about free treatment, place of availability, and its effectiveness. However, leprosy elimination campaign surveys may be used as a tool to filter large pool of cases from community.
\end{abstract}

\section{Introduction}

The annual new case load of leprosy in India has been reported to have declined significantly from $8.9 / 10,000$ in 2000 to $1.1 / 10,000$ in 2010 [1]. As per the latest data available [1], only 1.34 lakh new leprosy cases were reported in India during the year 2009-2010, and leprosy was declared eliminated on January 1, 2006, reaching the level of below 1 (0.98) per 10,000 population in India [2]. However, several reports [2-5] from Uttar Pradesh and Maharashtra [6, 7], India, and also from other countries such as Bangladesh [8] and Brazil [9] had indicated that leprosy case load may be many folds higher in India and elsewhere than as being reported under respective government health systems. This has created doubts $[10,11]$ about the actual achievements on leprosy control. The multidrug treatment (MDT) is very effective to cure the disease, and it is equally important and useful to assess the actual new case load of leprosy. A study was therefore undertaken with the following aims.

(1) To assess the burden of new undetected leprosy cases in two states through a population-based survey.

(2) Efficiency of case detection by ASHA workers as a local health functionary in general health system (GHS).

(3) Extended objective is also to compare government data with this survey to understand the extent of underreporting leprosy. 


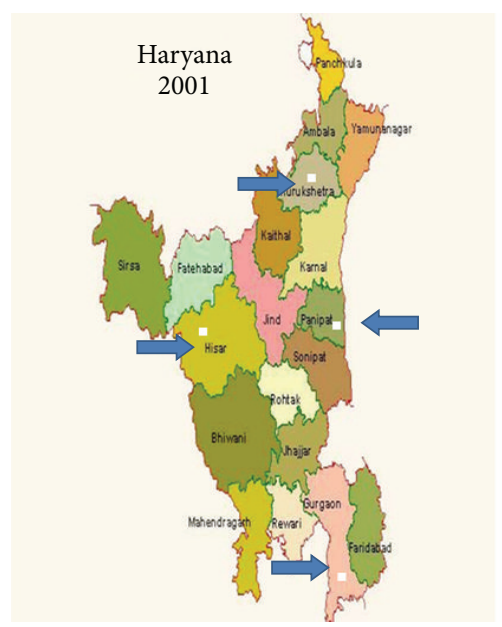

(a)

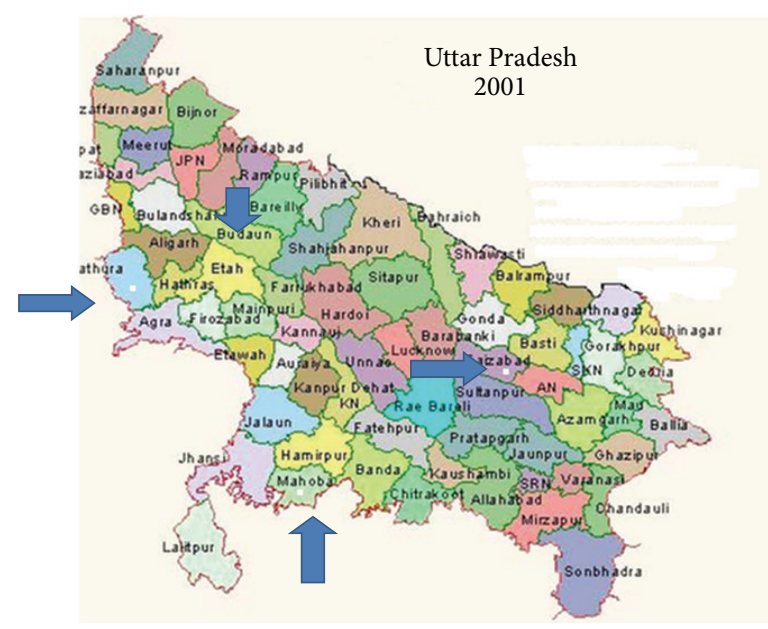

(b)

Figure 1: Arrow showing selected districts of Haryana and Uttar Pradesh.

TABLE 1: Details of selected districts and primary health centres (PHC) and subcentres (SC) in two selected states, India.

\begin{tabular}{|c|c|c|c|c|c|}
\hline State & Region & District & PHC to be selected randomly & Subcentre/PHC & Pop/Subcentre \\
\hline \multirow{4}{*}{ Uttar Pradesh } & $\mathrm{N}$ & Badaun & 4 & 4 & 5000 \\
\hline & $\mathrm{E}$ & Faizabad & 4 & 4 & 5000 \\
\hline & $\mathrm{W}$ & Mathura & 4 & 4 & 5000 \\
\hline & $S$ & Mahoba & 4 & 4 & 5000 \\
\hline \multirow{4}{*}{ Haryana } & $\mathrm{N}$ & Kurukshetra & 4 & 4 & 5000 \\
\hline & $\mathrm{E}$ & Panipat & 4 & 4 & 5000 \\
\hline & $\mathrm{W}$ & Hisar & 4 & 4 & 5000 \\
\hline & $S$ & Mewat & 4 & 4 & 5000 \\
\hline
\end{tabular}

\section{Methodology}

2.1. Selection of States. Two states in India were selected for the study-one highly endemic for leprosy (i.e., Uttar Pradesh or U.P.) and another with low endemicity for leprosy (i.e., Haryana).

2.2. Sampling Design. In each state, 4 districts were randomly selected after dividing the state into 4 clusters, that is, North, East, West, and South. In each district, 4 PHCs were selected randomly using random number table. Under each selected PHC, 4 subcentres were randomly selected using cluster sampling approach for population survey to search for leprosy cases. The average population size of PHC in U.P. was about 36,000, and in Haryana, it was slightly lower.

Although urban areas were to be surveyed by JALMA team (JT) and rural areas by ASHA workers, JT also surveyed rural areas initially due to either nonavailability or inability of ASHA workers to undertake the survey work and then reallocating one subcentre per PHC for reasons of comparing efficiency.

2.3. Sample Size. The central leprosy division (CLD) provided a national figure of disability prevalence as $2.5 / 10,000$ population. Assuming this figure $(P=0.00025)$ being lower than leprosy prevalence and $20 \%$ of error margin in this observation, the estimated sample size came out to be equal to 399900 per state. It is well known that design effect (DE) may be lower than 1 or more than one, so in the absence of data to compute design effect, DE was assumed as 1 . It was also proposed to select 4 districts from each state in such a manner that each district represents one cluster in areas belonging to North, East, West, and South of each state. Therefore, the size of population to be covered from each district was set equal to 100,000 . Further, 4 PHC clusters were randomly selected from each district and 4 subcentres from each PHC cluster. The distribution of the total population to be sampled in each district was subdivided as follows: $20 \%(20,000)$ of the size to be covered in urban areas and the rest $80 \%(80,000)$ from rural areas of 16 subcentres, that is, 80,000/district (Table 1 and Figure 1).

\section{Organization of Activities}

This was a cross-sectional survey, and no attempt was made to revisit the missed household for any reasons. The survey in rural areas was to be conducted using 20 village level ASHA (accredited social health activist) workers per PHC, and their field work was supervised by trained leprosy supervisors. These ASHA workers were trained to undertake house to 


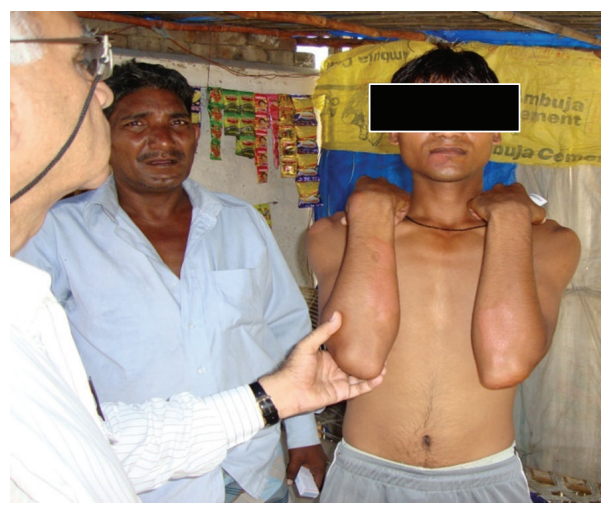

(a)

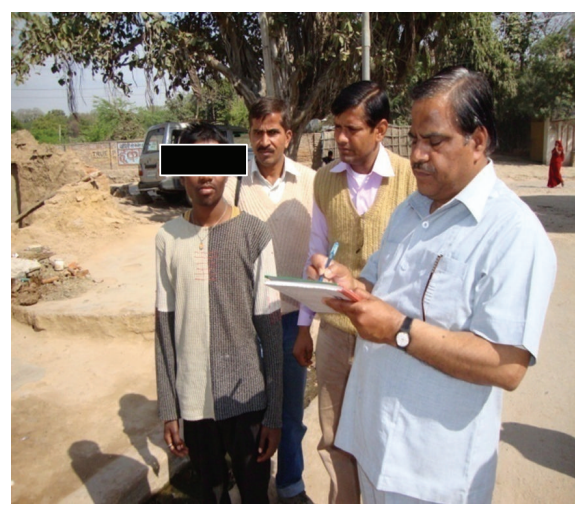

(b)

FiguRE 2: New leprosy cases being cross-examined by leprosy expert from health ministry (a) in Mewat of Haryana and district leprosy officer, Mahoba, in Uttar Pradesh (b).

house survey in their villages to initially identify suspect cases of leprosy and leprosy-related disability using the scheduled questionnaire. The supervisors then visited these suspects to first filter noncases and then having the remaining cases cross-examined and confirmed clinically by respective PHC doctor. The standard MDT was then provided by the doctor at PHC in rural areas.

In urban areas, the survey was conducted by a team from JALMA having 6 males and 1 female field workers with 35 years of experience in leprosy, 4 male trained paramedical (PMW) supervisors with 5-8 years of experience of work in leprosy (same team is used for all urban areas). The PMW supervisors first examined the suspect and then cross-verified by the district leprosy officer. Once confirmed, the treatment was given under supervision of the district leprosy officer and necessary records were maintained.

3.1. Timings of Survey Activities. The field work for this house to house survey was started on May 1, 2009, and finished by April 30, 2010. The survey was conducted only during daytime (7 AM to $4 \mathrm{PM}$ ), and physical examination method was used to detect leprosy cases.

3.2. Training to ASHA. Initially 2 days comprehensive training programme was conducted for ASHA workers at each selected PHC in selected districts. During the training, audiovisuals describing all aspects of a leprosy case, disability, and how to differentiate it from nonleprosy were taught. An active leprosy case demonstration was also done. Each ASHA worker was provided with a complete survey kitbag containing survey questionnaire, writing board, pen, stapler, pamphlets, case demonstration card, and so forth.

3.3. New Leprosy Case and Treatment. A person with hypopigmented or reddish skin patches(s) and with definite signs of anesthesia and with or without nerve involvement but with no history of leprosy treatment was classified as a new case of leprosy irrespective of duration of disease. These cases were previously undiagnosed plus new cases in recent times.
A confirmed leprosy case with 1-5 skin lesions with/without 1 thicken nerve is classified as pau- cibacillary (PB) leprosy and with 6 or more skin lesions and with 2 or more thicken nerves as multibacillary $(M B)$ leprosy. A neuritic case of leprosy is defined as the one without skin patches and with one or more nerve involvements.

The standard W.H.O. MDT treatment was provided through the respective $\mathrm{PHC}$ in rural and through the district leprosy officer in urban areas after case confirmation as shown in Figure 2.

\begin{abstract}
Prevalent case was defined as the one who had either taken at least part of the treatment earlier or defaulted but still detected to have active disease. The self-reported case is defined as one who reported for treatment at any leprosy treatment centres in recent months and currently continuing treatment. These are new cases and still not declared cured or release from treatment.
\end{abstract}

\section{Data Management and Statistical Analysis}

The survey data was collected using questionnaire schedules having closed and open-ended questions. These were checked in the field and then transported to JALMA Agra for data entry work. The quality of data entry was checked before data analysis and report writing. For assessing the leprosy new case load, all the leprosy cases (new untreated and self-reported) were added to compute new case detection rate (NCDR). $\chi^{2}$-test has been used to compare the significance difference between the prevalence.

\section{Results}

5.1. Active New Case Detection Rate (ANCDR). In Uttar Pradesh (UP), a total of 276 cases were detected, and the 
TABle 2: New case detection rate in selected districts of Uttar Pradesh and Haryana during 2009-10.

\begin{tabular}{|c|c|c|c|c|c|c|c|}
\hline \multirow{3}{*}{$\begin{array}{l}\text { District } \\
\text { surveyed }\end{array}$} & \multirow{3}{*}{$\begin{array}{l}\text { Population } \\
\text { examined }\end{array}$} & \multicolumn{2}{|c|}{ Actual new leprosy cases } & \multirow{3}{*}{$\begin{array}{c}\text { Active } \\
\text { cases- } \\
\text { prevalent } \\
\text { Total }\end{array}$} & \multirow{2}{*}{\multicolumn{3}{|c|}{$\begin{array}{c}\text { Actual new leprosy cases } \\
\text { Actual NCDR/10,000 population }\end{array}$}} \\
\hline & & \multirow{2}{*}{$\begin{array}{l}\text { Detected in survey } \\
\text { (A) }\end{array}$} & \multirow{2}{*}{$\begin{array}{l}\text { Self-reported for } \\
\text { treatment } \\
\text { (B) }\end{array}$} & & & & \\
\hline & & & & & $\begin{array}{c}\text { Survey } \\
\text { (A) }\end{array}$ & $\begin{array}{l}\text { Self-reported } \\
\text { (B) }\end{array}$ & $\begin{array}{c}\text { Total } \\
(\mathrm{A}+\mathrm{B})\end{array}$ \\
\hline U.P. & 399540 & 269 & 7 & 8 & 6.73 & 0.18 & 6.91 \\
\hline Mathura & 98920 & 12 & 1 & 0 & 1.21 & 0.10 & 1.31 \\
\hline Badaun & 108126 & 134 & 1 & 5 & 12.39 & 0.09 & 12.49 \\
\hline Mahoba & 96333 & 47 & 1 & 2 & 4.88 & 0.10 & 4.98 \\
\hline Faizabad & 96161 & 76 & 4 & 1 & 7.90 & 0.42 & 8.32 \\
\hline Haryana & 404996 & 73 & 6 & 1 & 1.80 & 0.15 & 1.95 \\
\hline Mewat & 101696 & 10 & 0 & 0 & 0.98 & 0 & 0.98 \\
\hline Hisar & 109508 & 1 & 3 & 0 & 0.09 & 0.27 & 0.36 \\
\hline Panipat & 102653 & 29 & 1 & 1 & 2.82 & 0.10 & 2.92 \\
\hline Kurukshetra & 91139 & 33 & 2 & 0 & 3.62 & 0.22 & 3.84 \\
\hline Total & 804536 & 342 & 13 & 9 & 4.25 & 0.16 & 4.41 \\
\hline
\end{tabular}

TABLE 3: Percent MB leprosy detected in survey and in self-reported cases in selected districts of Uttar Pradesh and Haryana during 2009-10.

\begin{tabular}{|c|c|c|c|c|c|c|c|c|c|}
\hline \multirow[t]{2}{*}{ District surveyed } & \multicolumn{3}{|c|}{$\begin{array}{l}\text { New leprosy cases } \\
\text { Detected in survey }\end{array}$} & \multicolumn{3}{|c|}{ Self-reported and prevalent cases } & \multicolumn{3}{|c|}{$\begin{array}{c}\text { Total prevalent cases } \\
\text { detected in survey }\end{array}$} \\
\hline & Total & $\mathrm{MB}$ & $\% \mathrm{MB}$ & Total & $\mathrm{MB}$ & $\% \mathrm{MB}$ & Total & $\mathrm{MB}$ & $\% \mathrm{MB}$ \\
\hline Uttar Pradesh & 269 & 64 & 23.8 & 15 & 10 & 66.7 & 284 & 74 & 26.1 \\
\hline 1 Mathura & 12 & 4 & 33.3 & 1 & 1 & 100.0 & 13 & 5 & 38.5 \\
\hline 2 Badaun & 134 & 32 & 23.9 & 6 & 4 & 66.7 & 140 & 36 & 25.7 \\
\hline 3 Mahoba & 47 & 13 & 27.7 & 3 & 1 & 33.3 & 50 & 14 & 28.0 \\
\hline 4 Faizabad & 76 & 16 & 21.1 & 5 & 4 & 80.0 & 81 & 20 & 24.7 \\
\hline Haryana & 73 & 22 & 30.1 & 7 & 5 & 71.4 & 80 & 27 & 33.8 \\
\hline 1 Mewat & 10 & 4 & 40.0 & 0 & 0 & 0 & 10 & 4 & 40.0 \\
\hline 2 Hisar & 1 & 0 & 0 & 3 & 3 & 100.0 & 4 & 3 & 75.0 \\
\hline 3 Panipat & 29 & 5 & 17.2 & 2 & 1 & 50.0 & 31 & 6 & 19.4 \\
\hline 4 Kurukshetra & 33 & 13 & 39.4 & 2 & 1 & 50.0 & 35 & 14 & 40.0 \\
\hline All & 342 & 87 & 25.4 & 22 & 15 & 68.2 & 364 & 102 & 28.0 \\
\hline
\end{tabular}

NCDR was observed to be 6.91 per 10,000 populations surveyed. Of this, $2.54 \%$ (7/276) were self-reported cases and the rest were new untreated or previously undiagnosed cases. In Haryana, where a total of 79 new cases were detected and NCDR of 1.95 per 10,000 populations, of this, $7.59 \%$ $(6 / 79)$ were self-reported (Table 1$)$. The district Badaun in UP was observed to have the highest (see Table 2) NCDR/10,000 population of 12.49 followed by Faizabad (8.32), Mahoba (4.98), and the lowest in Mathura (1.31). Similarly in Haryana, the highest NCDR/10,000 population of 3.84 was recorded in Kurukshetra district followed by Panipat (2.92), Mewat (0.98), and the lowest (0.36) in Hisar district. The data suggests that the overall NCDR/10,000 on account of selfreported cases was 0.16 and accounted for $3.66 \%$ (13/355) only in both the states put together. The combined NCDR/10,000 population was 4.41 per 10,000 populations.
The share of multibacillary (MB) leprosy cases was $23.8 \%$ $(64 / 269)$ in UP and $30.1 \%$ (22/73) in Haryana. However, MB in self-reported cases along with prevalent cases was $66.7 \%$ $(10 / 15)$ in UP and $71.4 \%(5 / 7)$ in Haryana. In both states together, $\mathrm{MB}$ disease was $25.4 \%$ (87/342) in new detected cases and $68.2 \%(15 / 22)$ among those self-reported and prevalent cases.

The overall MB disease was $28.0 \%(102 / 364)$ of the total active leprosy cases in this survey (Table 3 ).

\section{ANCDR by Age and Sex}

The new case detection rate (NCDR/10,000 population) by age has shown increasing trend from the lowest of 0.96 to 20.72 at the age of 60 years and above. The age pattern seems to have the same trend for males and females in UP and 
TABLE 4: NCDR/10,000 population by age and sex detected in Uttar Pradesh and Haryana, 2009-10.

\begin{tabular}{|c|c|c|c|c|c|c|}
\hline \multirow{2}{*}{ Age groups } & \multicolumn{2}{|l|}{ Males } & \multicolumn{2}{|l|}{ Females } & \multicolumn{2}{|l|}{ Total } \\
\hline & Population (new cases) & NCDR/10,000 & Population (new cases) & NCDR/10,000 & Population (new cases) & NCDR/10,000 \\
\hline \multicolumn{7}{|c|}{ Uttar Pradesh } \\
\hline $0-9$ & $54587(5)$ & 0.92 & $49286(05)$ & 1.01 & $103873(10)$ & 0.96 \\
\hline $10-19$ & $55703(22)$ & 3.95 & $50813(25)$ & 4.92 & $106516(47)$ & 4.41 \\
\hline $20-29$ & $30458(22)$ & 7.22 & $33191(14)$ & 4.22 & $63649(36)$ & 5.66 \\
\hline $30-39$ & $22789(20)$ & 8.78 & $25804(32)$ & 12.40 & $48593(52)$ & 10.70 \\
\hline $40-49$ & $16405(23)$ & 14.00 & $16252(21)$ & 12.92 & $32657(44)$ & 13.47 \\
\hline $50-59$ & $9530(18)$ & 18.88 & $9621(17)$ & 17.67 & $19151(35)$ & 18.28 \\
\hline$>59$ & $12637(30)$ & 23.74 & $12464(22)$ & 17.65 & $25101(52)$ & 20.72 \\
\hline Total & $202109(140)$ & 6.93 & $197431(136)$ & 6.89 & $399540(276)$ & $6.91^{*}$ \\
\hline \multicolumn{7}{|c|}{ Haryana } \\
\hline $0-9$ & $54181(4)$ & 0.74 & $45242(6)$ & 1.33 & $99423(10)$ & 1.01 \\
\hline $10-19$ & $52740(11)$ & 2.09 & $44399(6)$ & 1.36 & $97139(17)$ & 1.75 \\
\hline $20-29$ & $35734(5)$ & 1.40 & $37837(7)$ & 1.85 & $73571(12)$ & 1.63 \\
\hline $30-39$ & $23778(6)$ & 2.52 & $26490(8)$ & 3.02 & $50268(14)$ & 2.79 \\
\hline $40-49$ & $19116(8)$ & 4.18 & $17933(6)$ & 3.33 & 37049 (14) & 3.78 \\
\hline $50-59$ & $9982(2)$ & 2.00 & $9362(1)$ & 1.07 & $19344(3)$ & 1.55 \\
\hline$>59$ & $14453(7)$ & 4.84 & $13749(2)$ & 1.45 & $28202(9)$ & 3.19 \\
\hline Total & $209984(43)$ & 2.05 & $195012(36)$ & 1.85 & $404996(79)$ & $1.95^{*}$ \\
\hline
\end{tabular}

${ }^{*}$ OR $(95 \% \mathrm{CI})=3.55(2.76-4.55), \chi^{2}=112, P<0.0001$.

TABLE 5: Number of skin lesions and number of nerves involvement.

\begin{tabular}{lcccccc}
\hline No. of lesions & \multicolumn{2}{c}{ No. of nerves } & \multicolumn{2}{c}{ Total (percent) } \\
\hline 0 & 0 & 1 & $2-3$ & $4-5$ & 4 & $18(5.1)$ \\
1 & 0 & 4 & 6 & 0 & 0 & $168(47.3)$ \\
$2-3$ & 136 & 32 & 0 & 0 & 0 & $78(22.0)$ \\
$4-5$ & 48 & 28 & 2 & 0 & 3 & $14(3.9)$ \\
$6-10$ & 8 & 3 & 2 & 12 & $24(6.8)$ \\
$>10$ & 9 & 2 & 10 & $19(5.4)$ & $24(6.8)$ & $53(14.9)$ \\
\hline Total (percent) & 12 & $74(20.8)$ & $25(7.0)$ & & $355(100.0)$ \\
\hline
\end{tabular}

Haryana, since no sex difference was observed. However, NCDR was significantly (3.55 times) higher in UP than in Haryana (per person NCDR 0.000691 versus $0.000195, \chi^{2}=$ $112, P<0.0001)$ (Table 4$)$.

\section{Number of Skin Lesions and Nerves}

Of the total 355 new cases in this survey, a large amount of $47.3 \%$ had just a single skin lesion and $81 \%$ of these without any thickened nerve. Of the total, 78 cases (22\%) had 2-3 skin lesions and 53 cases (14.9\%) with 10 or more skin lesions. However, $5.1 \%$ were neuritic cases.

Similarly, 213 cases $(60 \%)$ of the total new cases had no nerve involvement, $74(20.8 \%)$ had only one thickened nerve, and $24(6.8 \%)$ with 5 or more thickened nerves (Table 5).

\section{ANCDR in Urban versus Rural Areas}

The data presented in Table 6 revealed that the ANCDR/ 10,000 population in urban area of U.P. was 9.76 and 7.94 in Haryana, respectively. The ANCDR in rural areas of U.P. was 6.12, which is significantly higher than the figure of 0.31 in Haryana $\left(\chi^{2}=166.7, P<0.0001\right)$. In the total population of the two states, ANCDR in rural area was 3.20 in comparison to 8.85 in urban areas $\left(\chi^{2}=98.3, P<0.0001\right)$.

\section{ANCDR by JALMA Team versus ASHA in Rural Areas}

The NCDR/10,000 population surveyed by ASHAs was 0.75: 1.51 in U.P. and 0.08 in Haryana. The NCDR in population surveyed by JALMA team (JT) was observed as 13.12; 20.92 in 
TABLE 6: ANCDR per 10,000 populations surveyed by rural urban status, 2009-10.

\begin{tabular}{|c|c|c|c|c|c|c|c|c|c|}
\hline \multirow[b]{2}{*}{ State } & \multicolumn{3}{|c|}{ Rural } & \multicolumn{3}{|c|}{ Urban } & \multicolumn{3}{|c|}{ Total } \\
\hline & $\begin{array}{c}\text { Popn } \\
\text { examined }\end{array}$ & $\begin{array}{c}\text { Leprosy } \\
\text { cases }\end{array}$ & ANCDR & $\begin{array}{c}\text { Popn } \\
\text { examined }\end{array}$ & $\begin{array}{c}\text { Leprosy } \\
\text { cases }\end{array}$ & ANCDR & $\begin{array}{c}\text { Popn } \\
\text { examined }\end{array}$ & $\begin{array}{c}\text { Leprosy } \\
\text { cases }\end{array}$ & ANCDR \\
\hline U.P. & 313493 & 192 & 6.12 & 86047 & 84 & 9.76 & 399540 & 276 & 6.91 \\
\hline Haryana & 318125 & 10 & 0.31 & 86871 & 69 & 7.94 & 404996 & 79 & 1.95 \\
\hline Total & 631618 & 202 & 3.20 & 172918 & 153 & 8.85 & 804536 & 355 & 4.41 \\
\hline$\chi^{2}, P$ value & \multicolumn{3}{|c|}{$166.7,<0.0001$} & \multicolumn{3}{|c|}{$1.62,0.20$} & \multicolumn{3}{|c|}{$112,<0.0001$} \\
\hline
\end{tabular}

TABLE 7: ANCDR per 10,000 population surveyed by Jalma team versus ASHA in rural areas.

\begin{tabular}{lcccccccc}
\hline State & $\begin{array}{c}\text { Popn } \\
\text { examined }\end{array}$ & $\begin{array}{c}\text { Leprosy } \\
\text { cases }\end{array}$ & ANCDR & $\begin{array}{c}\text { Popn } \\
\text { examined }\end{array}$ & $\begin{array}{c}\text { (B) ASHAs } \\
\text { Leprosy } \\
\text { cases }\end{array}$ & ANCDR & $\begin{array}{c}\chi^{2} \text { (JALMA } \\
\text { Ratio (A/B) } \\
\text { versus ASHAs), } \\
P \text { value }\end{array}$ \\
\hline U.P. & 74549 & 156 & 20.92 & 238944 & 36 & 1.51 & 13.85 & $350.0,<0.00001$ \\
Haryana & 50438 & 8 & 1.59 & 267687 & 2 & 0.08 & 19.88 & $30.8,<0.0001$ \\
\hline Total & 124987 & 164 & 13.12 & 506631 & 38 & 0.75 & 17.49 & $479.9,<0.00001$ \\
\hline
\end{tabular}

UP and 1.59 in Haryana. The comparison of the NCDR figures from ASHAs work with JALMA team, that is, (0.75 versus 13.12) suggests that JALMA team had helped in detecting more leprosy cases in rural areas, that is, 17.5 times (13.12 versus 0.75 ); 13.9 times (20.92 versus 1.51) in U.P.; 19.9 times (1.59 versus 0.08 ) in Haryana, (Table 7).

\section{Discussion}

The estimated errors in the observed ANCDR of 0.000691 in 399540 population of Uttar Pradesh and 0.000195 in 404996 population of Haryana are $12 \%$ and $22 \%$, respectively, as against the $20 \%$ assumed while computing sample size, indicating fair amount of acceptability of the survey data results. The study detected 342 new undetected leprosy cases and 13 self-reported cases with $47.3 \%$ single lesion cases (early leprosy). Data also suggested that MB disease in cases detected in survey was $25.4 \%$ as compared to high $\mathrm{MB}$ rate $(68.2 \%)$ (Table 3 ) in self-reported cases. No significant difference was found in NCDR by sex.

The study therefore provided input data to compare with programme data and its characteristics. For example, data collected by ASHA has revealed typically low level of detection rate in the community (1 in 17.5) (Table 7) and high $\mathrm{MB}$ rate $(68.2 \%)$ (Table 3 ) in self-reported cases as routinely being seen in Government reported data from general health system.

The voluntary reporting system for leprosy patients has some inherent problems related to the low level of community awareness, high social stigma, atypical skin lesions, and dependence on neurological symptoms which present late. On the contrary, active case searching in the community facilitates early case detection thereby reducing the probable risk of permanent disabilities and interrupting the ongoing transmission. Although as per the "Global Strategy for Further Reducing the Leprosy Burden and Sustaining Leprosy Control Activities 2006-2010", National Leprosy Programmes are urged to encourage people to come forward for treatment and recommends integrating leprosy services to health facilities [12].

Active case detection reveals that there are a large number of previously undetected leprosy cases in the population. The study in Agra district too had revealed that leprosy prevalence in the district was $16.4 / 10,000$ population [4] in comparison to 0.58 reported by district health authorities. A sample survey from Mumbai showed that $86 \%$ of the 79 newly detected cases did not report to the health systems despite having skin patches. This high proportion of undetected cases was rightly interpreted as a limitation of the impact of IEC activities [7]. A recent study from north-western Bangladesh depicted similar findings with a prevalence of previously undiagnosed leprosy of about (13.1 per 10,000 population) compared to the figure of registered leprosy cases (2.31 per 10,000 population) [9]. Another study in Brazil showed that $28.4 \%$ of leprosy cases in the community were not identified by the health system between 2001-2005 [13].

One of the reasons for new leprosy cases not getting registered could be that the leprosy at an early stage does not bother patients, and thus patients often ignore as there is no urgency of treatment. It is evident that a large proportion (47.3\%) of newly detected patients in the present study were single skin lesion cases, and $81 \%$ of these cases were without any nerve involvement. Other studies also reported high proportion (35.7\%) [6] of single lesion leprosy. Secondly, the NLEP curtailed registration of patients with single skin lesions by 2005 under the premise of misdiagnosis of other dermatological conditions as leprosy [12]. This might have deprived the patients of timely treatment and prevention of deformity but might have promoted transmission of leprosy in the community through single lesion cases which have been reported to be even multibacillary at times.

\section{Magnitude of the Leprosy Burden}

The Present study has suggested that the actual new case detection rate (ANCDR) was observed to be 4.41 per 10,000 
TABLE 8: Estimated population and ANCDR in Haryana and Uttar Pradesh-a comparison.

\begin{tabular}{|c|c|c|c|c|c|c|}
\hline State & Districts & Year & $\begin{array}{l}\text { Estimated } \\
\text { population }\end{array}$ & $\begin{array}{c}\text { New cases } \\
\text { detected }\end{array}$ & NCDR/10,000 P & $\begin{array}{c}\text { Ratio to } \\
\text { weighted } \\
\text { NCDR to this } \\
\text { survey }\end{array}$ \\
\hline \multirow{9}{*}{ Haryana } & \multirow{4}{*}{$\begin{array}{l}4 \text { selected } \\
\text { (A) }\end{array}$} & 2006-07 & 3914056 & 95 & 0.24 & \multirow{4}{*}{9.3} \\
\hline & & 2007-08 & 4992855 & 129 & 0.26 & \\
\hline & & 2008-09 & 4979716 & 66 & 0.13 & \\
\hline & & Weighted mean & - & - & 0.21 & \\
\hline & This survey & $2009-10$ & 404996 & 79 & 1.95 & 1.0 \\
\hline & \multirow{4}{*}{$\begin{array}{l}\text { All } 13 \\
\text { (B) }\end{array}$} & $2006-07$ & 24406898 & 502 & 0.21 & \multirow{4}{*}{10.8} \\
\hline & & 2007-08 & 25009748 & 379 & 0.15 & \\
\hline & & 2008-09 & 26497407 & 451 & 0.17 & \\
\hline & & Weighted mean & - & & 0.18 & \\
\hline \multirow{9}{*}{ Uttar Pradesh } & \multirow{4}{*}{$\begin{array}{l}4 \text { selected } \\
(\mathrm{C})\end{array}$} & 2006-07 & 9095610 & 1188 & 1.31 & \multirow{4}{*}{5.4} \\
\hline & & $2007-08$ & 9304809 & 1232 & 1.32 & \\
\hline & & 2008-09 & 9518819 & 1158 & 1.22 & \\
\hline & & Weighted mean & & & 1.28 & \\
\hline & This survey & 2009-10 & 399540 & 276 & 6.91 & 1.0 \\
\hline & \multirow[b]{2}{*}{ All 70} & $2006-07$ & 190326929 & 32413 & 1.70 & \multirow{4}{*}{4.4} \\
\hline & & 2007-08 & 194704448 & 31028 & 1.59 & \\
\hline & \multirow[t]{2}{*}{ (D) } & 2008-09 & 199182650 & 27577 & 1.39 & \\
\hline & & Weighted mean & & & 1.56 & \\
\hline
\end{tabular}

populations surveyed in comparison to national figure of 1.09 per 10,000 populations recorded during 2009-2010. The ratio is 4.05 (4.41/1.09). Since large population of the survey, $80.2 \%$ (506631/631618) had been surveyed by ASHA workers, and the effectiveness of ASHA in the leprosy case detection is observed to be low leading to suggest that if the population surveyed by ASHA would have been surveyed by experienced JALMA team or alike, the ANCDR in rural areas might have increased to 13.12 . The ANCDR per 10,000 population in India after adjusting for team's performance suggests that it could be about 10.64 instead of 4.41 . The ratio with national data is therefore arrived at $9.76(10.64 / 1.09)$. It can thus be suggested that ANCDR in India could be in the range of 4.05 times to 9.76 times higher than the reported national ANCDR of 1.09 in 2009-2010 as per Government records.

Similarly, when compared with district data (weighted for last 3 years), it suggests that ANCDR in Haryana may be 9.3 to 10.8 times and in Uttar Pradesh 4.4 times to 5.4 times higher than the reported levels during 2009-2010 (Table 8). However, this comparison is under the assumption if observed rates representative of the state and national level data.

\section{Policy Implications}

The wide gap between the estimated new case detection rate (NCDR) of leprosy obtained by active case detection and projected ANCDR obtained by passive case reporting underscores the efficiency and need for active case detection in leprosy in order to obtain the actual burden of disease.
However, in view of limited resources in the public health system, it may not be possible to undertake the exercise of active case detection in the entire national population. Alternative methods may thus need to be considered to bring in large pool of untreated cases to treatment.

This study highlights the presence of a large number of undiagnosed or unreported cases of leprosy in the community in India based on sample survey data of 8 districts in Uttar Pradesh and Haryana. Numerous studies [3-9] have indicated the high occurrence of leprosy. The high burden of leprosy in the present study and also in other studies is certainly indicative of underscoring the real leprosy problem in the country and ignoring the variable degree of active but confirmed transmission of leprosy in the study population. This also has logistic implications in terms of treatment supplies to subdistrict or health facilities in the country.

In most active field surveys, the $\mathrm{MB}$ proportion remains under $30 \%$ as against the high proportion of multibacillary cases, often above $50-80 \%$ in data from passive reporting, indicating that many early leprosy cases missed out in passive reporting system [14]. This finding also correlates well with high transmission in areas of high $\mathrm{MB}$ ratio. Thus, a policy for active case detection, in selective areas of high $\mathrm{MB}$ ratio (>40\%), would aid in the estimation of the real burden of leprosy. This would also facilitate the policy for prevention of deformity in addition to the provision of timely and adequate treatment and rehabilitation support to the patients.

One of the cornerstones of National Leprosy Elimination Programme is information, education, and communication 
(IEC) in the community. The government has also partnered with various nongovernmental organizations in order to increase the level of awareness with regard to leprosy at community level and to improve self-reporting. Despite significant financial and human investment by the government of India over decades, the impact of IEC seems to be very limited. It is therefore the need of the time that leprosy control programmes are designed to use easy IEC messages to sufficiently motivate population for self-examination and reporting to health system. In addition, health system must improve its health care delivery so that more people get motivated to participate and utilize the services. This should help to reduce the leprosy burden in actual terms.

\section{Conflict of Interests}

The authors declare that they have no conflict of interests.

\section{Acknowledgment}

The authors thank the help received from Health staff of Haryana and Uttar Pradesh for the study. Present work is an offshoot of a study conducted by the authors for WHO "assessment of disability burden in India with special reference to leprosy" under WHO Grant no. SE/09/206259. However, responsibility of data collected and observations made are not of WHO.

\section{References}

[1] Central Leprosy Division, "NLEP-progress report for the year 2009-10 ending on 31st March 2010," Directorate General of Health Services, Nirman Bhawan, New Delhi, http://www.nlep nic.in.

[2] "Announcement: India achieves national elimination of leprosy," Indian Journal of Leprosy, vol. 78, article 101, 2006.

[3] A. Kumar, A. Girdhar, V. S. Yadav, and B. K. Girdhar, "Some epidemiological observations on leprosy in India," International Journal of Leprosy and Other Mycobacterial Diseases, vol. 69, no. 3, pp. 234-240, 2001.

[4] A. Kumar, A. Girdhar, and B. K. Girdhar, "Epidemiology of leprosy in urban Agra," Leprosy Review, vol. 74, no. 1, pp. 31-34, 2003.

[5] A. Kumar, A. Girdhar, and B. K. Girdhar, "Prevalence of leprosy in Agra District (U.P.) India from 2001 to 2003," International Journal of Leprosy and Other Mycobacterial Diseases, vol. 73, no. 2, pp. 115-121, 2005.

[6] K. Anil, J. K. Chakma, V. S. Yadav, G. Anita, and B. K. Girdhar, "Leprosy scenario in Agra: epidemiological observations from rapid population survey 2004-06," Journal of Communicable Diseases, vol. 40, no. 4, pp. 277-284, 2008.

[7] V. P. Shetty, U. H. Thakar, E. D'Souza et al., "Detection of previously undetected leprosy cases in a defined rural and urban area of Maharashtra, Western India," Leprosy Review, vol. 80, no. 1, pp. 22-33, 2009.

[8] S. Kingsley, "Sample survey in Mumbai under the auspices of Municipal Corporation of Greater Mumbai. Session 2," in Proceedings of the National Workshop on Strategies for New Case Detection during Integration Phase: Experiences across Maharashtra, ALERT India, October 2007.
[9] F. J. Moet, R. P. Schuring, D. Pahan, L. Oskam, and J. H. Richardus, "The prevalence of previously undiagnosed leprosy in the general population of northwest Bangladesh," PLoS Neglected Tropical Diseases, vol. 2, no. 2, article e198, pp. 1-4, 2008.

[10] G. Mudur, "Doctors accuse India of massaging leprosy figures," British Medical Journal, vol. 330, no. 7500, p. 1104, 2005.

[11] T. Burki, "Fight against leprosy no longer about the numbers," The Lancet Infectious Diseases, vol. 10, no. 2, p. 74, 2010.

[12] World Health Organization, Global Strategy for Further Reducing the Leprosy Burden and Sustaining Leprosy Control Activities 2006-2010, World Health Organization, Geneva, Switzerland, 2005.

[13] M. A. F. Grossi, C. Moschioni, J. R. Lambertucci et al., "Estimation of hidden prevalence of leprosy during the period 2001-2005, in Minas Gerais, Brazil," in Proceedings of the 17th International Leprosy Congress, Hyderabad, India, February 2008.

[14] S. Noordeen, "The epidemiology of leprosy," in Leprosy, R. Hastings, Ed., p. 68, Churchill Livingstone, Edinburgh, UK, 1994. 


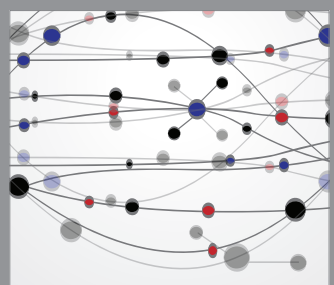

The Scientific World Journal
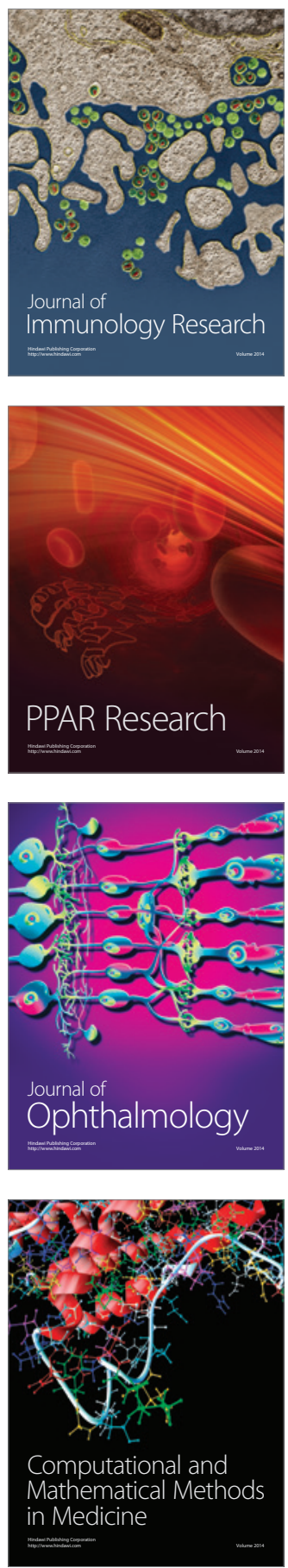

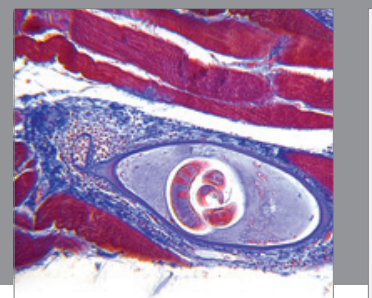

Gastroenterology

Research and Practice
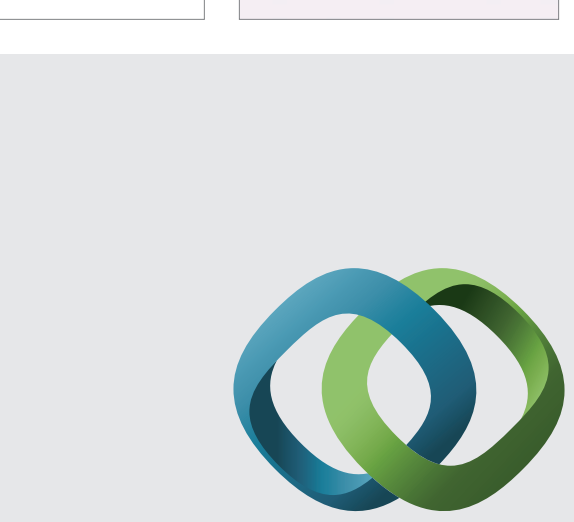

\section{Hindawi}

Submit your manuscripts at

http://www.hindawi.com
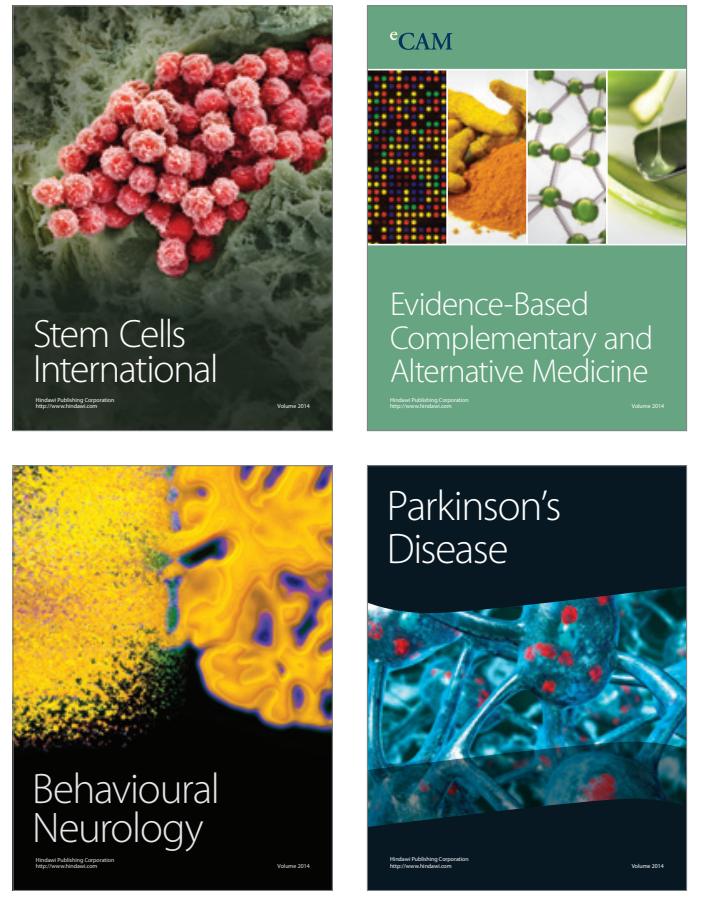
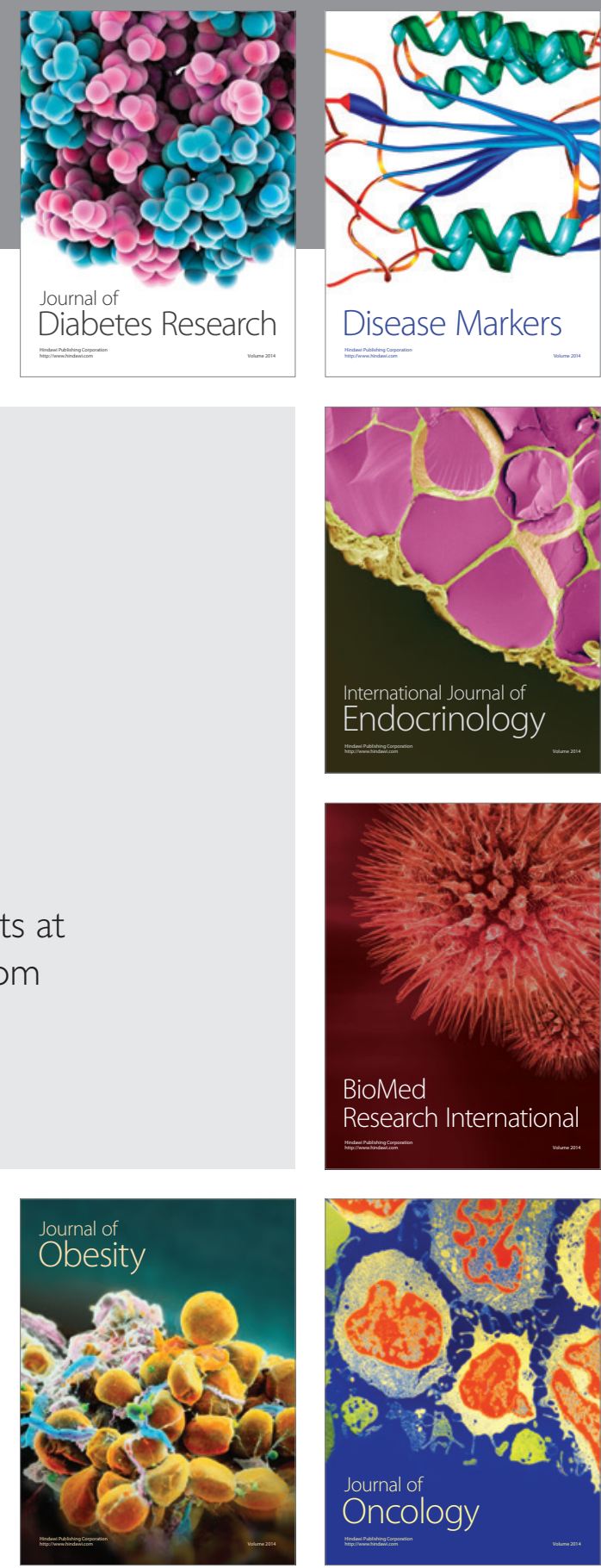

Disease Markers
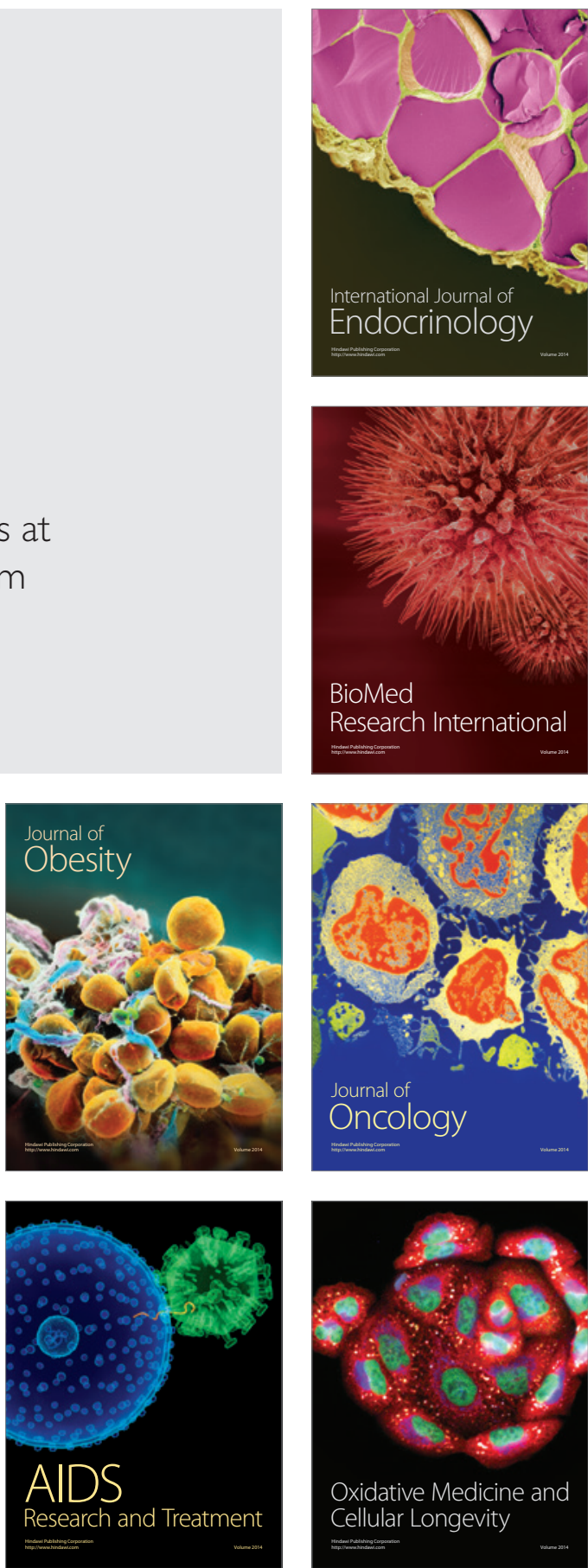